\title{
Dynamics of Trademark Dilution: Issues and Challenges in India and USA
}

\author{
Anuttama Ghose* \&o S.M. Aamir Ali**
}

\begin{abstract}
Trademarks of an establishment cannot solely be associated with identification of origin or source. It performs an imperative task of building brand name and value. The dilution theory rejects the opinion that the role of a trademark is solely based on the recognition of the root or source of its origin and that it is not only a figurative representation but carries a creative aspect as well. For the most recent decade, the greatest inquiry in trademark law has been the manner by which to demonstrate weakening or dilution. Dilution has turned out to be a dauntingly slippery idea. The principal issue with dilution law is that it gives a cure without a supportable hypothesis of the harm or damage. Even though lately the concept has been recognized in International as well as domestic jurisdiction putting an immense responsibility on domestic jurisdiction to protect trademarks against dilution, very little has been discussed or clarified regarding the theory of dilution. Ambiguity of such nature facilitated this research trying to spot some light on the theory of dilution comparing it from divergent angles in different jurisdictions. The paper also highlights the interpretation mechanism of the courts of the dilution provision and explains the concept further with reference to important cases under the U.S. laws and European judgments in the context of the Dilution laws and draws a comparative analysis of the effectiveness of the legal framework present in India with that of the USA.
\end{abstract}

\section{Introduction}

There is no doubt that application of trademarks can be traced back to ancient times. Marking the commodities and goods began in the early stages of civilization. In its most basic form a trademark can be defined as a source pointer but in reality a trademark is much more than just a marker of origin. Trademark doesn't necessarily specify the particular source or origin; instead it stipulates that the goods or services with which it is usually associated or affixed comes from the same source or channels which had previously provided a level of satisfaction. ${ }^{1}$ Therefore it delivers a sense of familiarity

\footnotetext{
Ms. Anuttama Ghose is an Assistant Professor of Law at Indian Institute of Legal Studies, Siliguri, Darjeeling (West Bengal), India. She can be reached at anuttamaghose@gmail.com.

** Mr. SM Aamir Ali is an Assistant Professor of Law at Indian Institute of Legal Studies, Siliguri, Darjeeling (West Bengal), India. He can be reached at smaamirali@nls.ac.in.

1 Frank I. Schechter, 'The Rational Basis of Trademark Protection', Harvard Law Review, p.813 volume 40:6, 1927, p. 833.
} 
and quality promise to the consumers. Consequently it plays a vital role in building a brand image. A trademark contrary to popular belief not only represents goodwill but also is a machinery of building such reputation and goodwill of the proprietor of such mark. ${ }^{2}$ The mark in itself is a selling instrument therefore the selling power or capability of the product depends largely on the mark and therefore it is of principal importance that the mark is not universal and incorporates some level of individuality.

It can safely be pronounced in this era that a trademark is an intangible property which similar to any tangible property can grow up to be an indispensable asset to any establishment or organization involved in the manufacturing of goods and services. Trademark which comprehends unique and coined words, name or symbol can not only be indicative of the source or root of the manufacturer but also help in building a brand or label. It influences the customer in such a manner that a reputed trademark can leave an impact in the minds of the people to the extent that association of such mark on some confusingly similar or dissimilar product can lead to assumption of that quality standard which is usually offered by the manufacturer of the original mark. From an economic perspective, a trademark can be a major contributor to the company earnings as it acts as an effective communication tool between the consumer and the manufacturer. Trademarks can easily communicate necessary intellectual aspects and information about the corporation, its standing, commodities and amenities through a single brand or symbol.

Therefore protecting the trademark from infringement has become of vital importance in this globalizing market of technology and innovation owing to the above mentioned benefits of the same. Needless to say, the trademark of a producer is said to be encroached when the same mark is used without authorization or permission by a third person on goods or services similar to the goods of the original owner with a view to baffle the consumer as to the origin or source of the product or service.

In order to grasp and analyze the notion of dilution profoundly the researchers are required to undergo an extensive research and review the existing data available on the conception of dilution, its evolution and current position across the different jurisdiction. After a thorough evaluation of the literature acquired, the following data and information has been found valuable by the researchers to further carry on her study built on these concepts:

The article, The Rational Basis of Trademark Protection by Frank I. Schechter ${ }^{3}$ who is recognized as the father of dilution theory, he while evolving the theory expressed that dilution can be explained as "the gradual whittling away or diffusion of the individuality and grasp upon the minds of the public at large of the trademark by associating it with goods of non-competing nature". The perception of consumer confusion as criteria of proving dilution has been opposed by Sarah Lux in her article Evaluating Trade Mark Dilution from the perspective of the Consumer ${ }^{4}$. As explained by her, any kind of damage

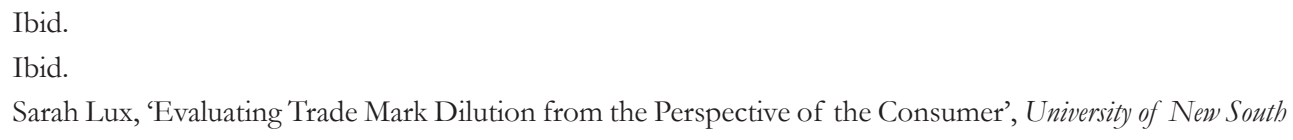


caused to any reputed mark even in the lack of confusion on the part of the consumer will be acknowledged as dilution of the said mark. Another perspective of dilution has been well established by T.G. Agitha in her article Trademark dilution- the Indian Approach ${ }^{5}$ that apart from absence of confusion in order to ascertain dilution it is necessary to prove that the similar mark has been used on dissimilar goods. She further contends that dilution like any other Trademark infringement should get equal protection and be treated at par with other infringements. Dilution has been categorized into two components by the author Courtland L Reichman in his article State and Federal Trademark Dilution 6 . He explains dilution as a phenomenon which without creating dilemma in the minds of the consumer regarding the source weakens the capability of the original mark to stand distinct in respect of source.

For drawing a comparison of the legal scenario in the context of dilution, the authors have gone through the book Trademark dilution: Federal, State and International law by David S. Welkowitz ${ }^{7}$. The book further educates the researcher regarding the modified State Dilution law sufficiently covering the defenses and remedies present there in as well as the recently adopted State laws mainly those inclined by the latest Model State Trademark Bill. Another article read by the author in this context is Anti-Dilution Law, New and Improved: The Trademark Dilution Revision Act of 2006 by Jennifer Files Beerline ${ }^{8}$. This article gives the researcher an insight of the shortcomings of the Federal Trademark Dilution Act which in turn led to the establishment of the Trademark Dilution Revision Act of 2006. Finally, the researcher widened her knowledge of the Dilution laws present in the Indian system by referring to the article The Polymorphism of Trademark. Dilution in India by Dev Gangjee ${ }^{9}$. The article provides a thorough explanation of the Dilution provision existing under the Trademarks Act 1999 with reference to features like reputation and dissimilar goods.

\section{Concept of Trademark Dilution}

A trademark becomes the identity of a producer. When such identity becomes global and gains universal recognition it becomes a brand and falls under the category of wellknown marks. When a famous or a well-known mark is infringed it causes dilution of such mark. Dilution is when one famous mark is infringed it loses its exclusivity. This causes erosion of the mark and it exhausts its stand-alone quality and its ability to be

Wales Law Journal p.1, volume 4:17, 2011, p. 2.

T.G. Agitha, 'Trademark Dilution - The Indian Approach', Journal of Indian Law Institute, p. 339 volume 50:1, 2008, p. 340.

${ }_{6}$ Reichman, Courtland, 'State and Federal Trademark Dilution', Franchise Law Journal volume 17:4, 1998, p.137.

7 David S. Welkowitz, 'Trademark Dilution: Federal, State and International Law', Bloomberg BNA, Second edition ISBN-13: 978-1617461033, December 28, 2012.

8 Jennifer Files Beerline, 'Anti-Dilution Law, New and Improved: The Trademark Dilution Revision Act of 2006', BerkeleyTech. Law Journal p. 511, volume 23, 2008.

9 Dev Gangjee, 'The Polymorphism of Trademark Dilution in India', Transnational Law \& Contemporary Problems p.230 volume17:1, 2008, p. 232. 
recognized clearly from a crowd of trademarks present in the global market.

For bringing a cause of action in case of dilution it is absolutely not necessary to prove presence of confusion or deception or the fact that the mark should be used on competing goods. ${ }^{10}$ Often dilution becomes a barrier for consumers to have a single association in mind when it comes to the famous mark. We can say this form of infringement easily brings down the reputation, fame and goodwill built by the owner of the well- known Mark in the Universal market through constant investment of capital, manpower and time.

Dilution follows two main categories of infringement that is dilution by blurring of the reputed mark and tarnishment of the same. Both contribute to the subsiding of the mark and take away the peculiarity of the well-known mark. Even though both of them fall under the category of dilution, there is dissimilarity between the two concepts.

- Dilution by Blurring: Blurring is the basic form that justifies the definition of dilution which speaks of the "gradual disperse" ${ }^{11}$ of the famous mark as stated by Schechter. ${ }^{12}$ When we say blur, we mean something that is not clear or not distinct. This concept can be understood by an imaginary example. As we all know the famous mark "DELL" is associated with Laptops but imagine DELL shampoos or DELL mattresses. In such cases the famous mark "DELL" is being associated with goods that are not in competition with laptops directly but the use of the same mark to point the source of origin of other products than the original one takes away the single association factor of the mark on the products of the original owner. This may not create a dilemma in the minds of the customer but does create a mental link. Now whenever one thinks of DELL it will not just pop the image of laptops but also other products on which such a mark has been associated as a source recognizer.

- Dilution by Tarnishment: A mark is said to be tarnished when it is used without authorization by a third party on such products which might create a negative notion in the minds of the consumer about that mark and thereby hurting the repute and status of the mark. ${ }^{13}$ How is tarnishment different from blurring? To answer this question we must understand that in order to establish tarnishment it is important to show that the original mark has been used or applied on products having substandard quality than the products of the original mark or the fact that the mark has been applied on products which

10 Courtland L. Reichman, 'State and Federal Trademark Dilution', Franchise Law Journal p. 111, volume.17:4, 1998, pp. 132-137.

11 Frank I. Schechter, 'The Rational Basis of Trademark Protection', Harvard Law Review p. 813 volume 40:6, 1927, p. 833.

12 Terry Ahearn, 'Dilution by Blurring under the Federal Trademark Dilution Act of 1995: What Is It and How Is It Shown', Santa Clara Law Review p.890, volume 41:1, 2001, p. 893.

13 Britt N. Lovejoy, 'Tarnishing the Dilution by Tarnishment Cause of Action: Starbucks Corp. v. Wolfe's Borough Coffee, Inc. and V Secret Catalogue, Inc. v. Moseley, Compared', Berkeley Tech. Law Journal p. 619, volume 26:1, 2011, p. 623. 
may not considered as dignified or products having objectionable images or notions. This creates a negative judgment in the minds of people. This negative association proves to be deadly for the owner who gained global reputation based on the quality guaranteed and provided for years.

In a landmark case, the famous brand Victoria's Secret ${ }^{14}$ instituted a suit for dilution against a small shop called Victor's little secret for selling a variety of products including adult videos, adult novelties and lingerie. This is a classic example of both dilution by blurring as well as tarnishment. Use of the mark 'VICTORIA'S SECRET' on adult products and vulgar coffee mugs is clearly degrading and tarnishing the original mark. While simply linking the mark on products of the defendant takes away the singular association of the mark and thereby causes a blurring effect in the minds of the people.

\section{Emergence of Dilution Theory from A Global Perspective}

Frank Schechter was the first person to theorize the concept of trademark dilution which according to him was the slow process of diffusion of the individuality and grasp on the public awareness of the mark by applying it on goods which are not in competition with each other. In the subsequent year an injunctive relief was granted against use of similar mark by defendant which was associated with dissimilar goods by Judge Learned Hand. ${ }^{15}$

Like most patterns in law, the dilution hypothesis was situated in custom-based law yet enunciated by a legitimate researcher. Frank I. Schechter laid the basis for dilution in his semi-yearly record of trademark protection, The Historical Foundations of the Law Relating to Trade-marks. The dilution model originated two years after this in another work by Schechter, The Rational Basis of Trademark Protection. ${ }^{16}$

\section{A. Evolution of Dilution in USA}

For the first part of the twentieth century the existence of direct competition was considered to be one of the main causes of action to establish trademark infringement and the concept of deception was not as spread-out like recent days as now it incorporates confusion not only limited to source but also comprises association, connection or validation. By the year 1920, there was a major shift in the then existing trademark law and also detection of a gap in the protection of trademark under the law in the U.S. With the advent of the twentieth century commercial dealings witnessed a drastic revolution.

It was first after the "Eastman Company Kodak Case" ${ }^{17}$ In England a considerable change

\footnotetext{
14 V Secret Catalogue, Inc. v. Moseley, 2001, 6 ${ }^{\text {th }}$ Circuit, 259 F.3d 464, p. 466.

15 Yale Electric Corporation V. Robertson, 1928, $2^{\text {nd }}$ Circuit 26 F.2d 972, p. 972.

16 Schechter, (n 1) pp. 813-833.

17 Eastman Photographic Materials Co Ltdv John Griffith S Cycle Corporation Ltd and Kodak Cycle Co Ltd.
} 
was observed in the conventional concept of trademark protection available in the United States. In this case Kodak Cycle Company was successfully prohibited from using the mark 'KODAK' on their cycles on the basis of the suit filed by Eastman Company who were manufacturers of Kodak cameras. An analysis of the judgment gives a clear understanding that the Court was of the opinion that confusion can occur even in absence of express competition of commodities. In reality the court was not explaining deception or confusion. It rather highlighted the importance and distinctive nature of the KODAK mark and how it should be protected to maintain its uniqueness. But in declaring such judgment the Court phrased it in a manner so as to remain consistent with the direct competition principle in respect to goods.

The judgment in Eastman Company became a precedent to be followed by the American Courts. A glorified instance of such can be seen in the case of Vogue Co. v. Thompson- Hudson Co. ${ }^{18}$ In this case the defendants Thompson and Hudson used the name VOGUE HATS and the trademark $\mathrm{V}$ on a line of hats produced and sold by them. This was claimed as a clear infringement of the trademark VOGUE BY Vogue Co. which used the letter $\mathrm{V}$ associated with a figure of a woman (V-GIRL) as its mark.

In another similar instance "Wall V. Rolls-Royce." 19 The Third Circuit Court of Appeals regulated that infringement principle was not only restricted to similar or competing goods. Here the mark ROLLS ROYCE was used on radio tubes. The court in order to justify infringement widened the scope of reason and clubbed radio tubes and automobiles as directly contending commodities on the basis of the fact electricity was an important element in case of automobiles and aeroplanes and one could assume that the company have extended its range of product to new electric using radio tubes. This was an attempt of the Court in applying traditional infringement principle to unconventional problems which made the element 'fame' a basis of dilution.

In 1932 efforts were indeed taken to establish a Federal Dilution Statute but were not successful owing to the resentment by the Department of Justice concerning the formation of property rights in trademarks. In this scenario the State Legislature turned out to be more accessible and almost 25 states were successful in establishing dilution Statutes ever since the year 1947.

\section{B. Implied application of Dilution in U.S. Courts}

The judgment in Eastman Company became a precedent to be followed by the American Courts. A glorified instance of such can be seen in the case of Vogue Co. v. Thompson- Hudson Co. ${ }^{20}$ In this case the defendants Thompson and Hudson used the name VOGUE HATS and the trademark $\mathrm{V}$ on a line of hats produced and sold by them. This was claimed as a clear infringement of the trademark VOGUE BY Vogue

\footnotetext{
1898, 15 R.P.C. 105.

18 Vogue Co. v. Thompson-Hudson Co., 1924, $6^{\text {th }}$ Circuit, 300 F. 509, p. 509.

19 Wall v. Rolls-Royce of America, Inc., 1925, $3^{\text {rd }}$ Circuit 4 F.2d 333, p. 335.

20 Schechter, (n 1) pp. 813-833.
} 
Co. which used the letter $\mathrm{V}$ associated with a figure of a woman (V-GIRL) as its mark.

In spite of the file being dismissed by the District Court the Sixth Court of Appeals overturned it stating that the defendant's use of the letter V was alike to V-GIRL which might risk the formation of the idea that the product of hat was produced, promoted or validated by the Plaintiff Company.

In this occasion, the court abstained from stretching out trademark protection to non-contending merchandise by referring to the couple of likenesses in the mark as transcendent. ${ }^{21}$ Fundamentally, the Vogue Court took after the lead of the Eastman Court and controlled the encroachment structure to allow relief without perceiving another reason of action.

In another similar instance "Wall V. Rolls-Royce." 22 The Third Circuit Court of Appeals regulated that infringement principle was not only restricted to similar or competing goods. Here the mark ROLLS ROYCE was used on radio tubes. The court in order to justify infringement widened the scope of reason and clubbed radio tubes and automobiles as directly contending commodities on the basis of the fact electricity was an important element in case of automobiles and aeroplanes and one could assume that the company have extended its range of product to new electric using radio tubes.

This was an attempt of the Court in applying traditional infringement principle to unconventional problems which made the element 'fame' a basis of dilution. The court was solely focusing on sale on the basis of deception or passing off goods in the twentieth century and consequently was massively struggling in finding damage in form of consumer confusion. When injury was sustained by the plaintiff even in absence of perplexity on part of the customer or damages to the sales, the court had no other choice but to expand and provide higher level of protection to such marks which were categorized as more unique and uncommon as compared to the rest in order to safeguard them from gradual diminishing and lessening of its distinctive stand-alone capacity owing to the unlawful use of the same by any third party. Accordingly the platform was arranged and dilution was recognized for the first time in the United States.

\section{Analyzing the scenario under Federal Trademark Dilution Act (FTDA) vis- à-vis scope}

Under the Federal Trademark Dilution Act (FTDA), only such marks which were considered famous even before the disputed mark has been used in trade and commerce for the first time were protected. ${ }^{23}$ The objective of FTDA was to safeguard the famous marks from experiencing a decline in their ability "to recognize and differentiate goods or services irrespective of existence or absence of competition among the proprietor of

\footnotetext{
21 Michael Adams, 'The Dilution Solution: The History and Evolution of Trademark Dilution', Tech. \& Intellectual. Property Law Journal p. 139, 2002, volume 2:1, p. 143.

22 Wall v. Rolls-Royce of America, Inc., 1925, 4 F.2d 333, p. 334.

23 Federal Trademark Dilution Act, 2006, United States of America, s. 1125(c)(1).
} 
the said famous mark and the unauthorized parties, or any possibility of misperception, error or deception". ${ }^{24}$ On analyzing the FTDA it can be fathomed that there existed a distinct lack of clarity in regards the subject matter and scope of protection.

The statute spoke of the famous mark eligibility but it failed to provide clarity on the definition of "famous" and what would be the necessary degree of fame to be considered as famous and be protected under the said anti-dilution statute. As a result there prevailed an ambiguity which resulted in different enforcement standards being adopted by different courts in the United States. Some courts took a more restricted approach than the others which were often in conflict with each other. ${ }^{25}$

The courts in the U.S. were often found to be in conflict with each other since the FTDA was not successful in defining the term "famous" with distinction. One major question which arose during such a period was whether the protection available under the anti-dilution statute covered only the naturally distinctive marks or whether it could be extended to marks which have attained the distinctiveness by their application of product of commerce over a given period of time. ${ }^{26}$

In the case of "New York Stock Exchange Inc. V. New York New York Hotel LLC"27 It was observed that the second circuit was of the opinion that only the marks which have naturally acquired distinctiveness could afford the protection under FTDA while on the other hand in the case of "Thane Intern., Inc. v. Trek Bicycle Corp." 28 The ninth circuit differed completely from such an opinion and was of the contrasting view.

In the former case the court was of the opinion that NYSE's marks lacked inherent distinctiveness and therefore notwithstanding the fact that it is famous the dilution allegations of NYSE were set aside since the anti-dilution shield under the Lanham Act encompasses only those marks that are fundamentally distinctive and not to those marks which have been successful in acquiring distinctiveness from ancillary meaning. In spite of NYSE's argument claiming the mark to be distinctive if not fundamentally but by means of acquired consequential meaning, it was not established whether the Act would cover those marks which are not integrally distinctive.

The similar view was maintained by the court in the case of "TCPIP Holding Co. v. Haar Communications Inc.," 29 and emphasis was given on the built distinctiveness of a mark.

Yet another conflict under the Act stirred up from the question whether trade dress and packaging would be covered under the FTDA and can avail the given protection? ? $^{30}$ Differences of opinion regarding this question was also witnessed in the decision of

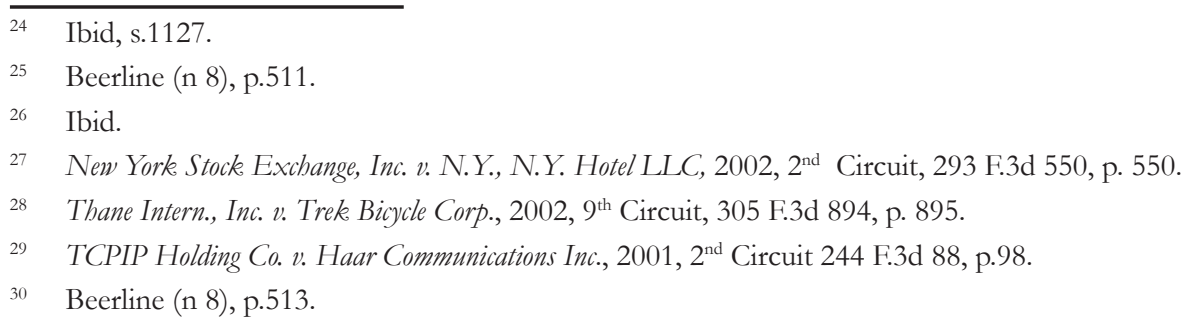


the U.S. courts. ${ }^{31}$ Even though the Act did not provide a certain definition of "famous" but it did manage to provide certain determinants based on which the fame can be determined under 1125(c)(1) of Federal Trademark Dilution Act, 2006, USA.

\section{Changes with Advent of Trademark Dilution Revision Act (TDRA)}

Subsequent to the decision in the case of Moseley v. V Secret Catalogue, Inc ${ }^{32}$., it was clear that there was an urgent need of modifying the Federal Statute and as a result the Revision Act was codified with the view of providing solutions for the existing gaps. The Trademark Dilution Revision Act 2006 brought some major changes to the Federal Trademark Dilution Act of 1996. The introduction of this Act led to the widening of the scope of rights of the proprietor of the famous marks and a better possibility of succeeding in the dilution claims.

With the advent of Trademark Dilution Revision Act (TDRA) the scope and subject matter of anti-dilution statute saw a considerable amount of change. Under the TDRA the standard was set much higher for marks to be regarded as "famous". Another development seen under the Revision Act was the recognition and inclusion of marks which have attained distinctiveness rather than being fundamentally distinctive under the scope of the Act including trade dress upon the fulfillment of certain conditions. But in spite of these changes, similar to FTDA discretion of the court persisted in following such directions and parameters.

With the introduction of the Trademark Dilution Revision Act the long continuing dispute over whether mark with attained distinctiveness and trade dress under the antidilution statute can avail the protection against dilution came to an end. Protection of trade dress has been expressly included under the new law as well as the above mentioned marks. ${ }^{33}$ As per the Act it is necessary for a trade dress to be famous independent of any registered mark contained within it and independent from that mark's reputation. ${ }^{34}$

This Act not only provides a well-defined primary requisite for fame it also requires country wise recognition and not just recognition restricted to any particular area. In this way it set the bar higher than the previous law for a mark to be considered famous. As per the TDRA, a famous mark would be one which is "extensively recognized by the usual consuming people". ${ }^{35}$ One similarity which persisted in the TDRA and FTDA is that the mark needs to be famous beforehand, that is before the offender uses the mark on his products or services. The TDRA clarifies that elucidating marks with gained uniqueness are qualified for security if well known. It was held by the Second

\footnotetext{
31 Nabisco, Inc. v. PF Brands, Inc., 1999, 2 $2^{\text {nd }}$ Circuit, 191 F.3d 208 p. 229; I. P. Lund Trading ApS v. Kobler Co.,1998, $1^{\text {st }}$ Circuit 163 F.3d 27, p. 50.

32 Moseley v. V Secret Catalogue Inc., 2003, 537 U.S. 418, p. 420.

33 Trademark Dilution Revision Act, 2006, United States of America, s. 1125(c) (1) (4).

34 Trademark Dilution Revision Act, 2006, United States of America, s. (c) (4) (B).

35 Trademark Dilution Revision Act, 2006, United States of America, s. 1125(c) (2) (A).
} 
Circuit in the TCPIP ${ }^{36}$ case that no protection under the FTDA would be accorded to descriptive marks.

The new Act has set the fame bar high as it states "extensively known among the common people". An analysis of the term suggests that having a reputation and being acknowledged among the niche trade area is not enough unless and until it is also widely identified among the consumer. It indicates that any company doing business with any organization may be very well-known in that particular industry or commerce sector but it won't meet the standards of fame set by the TDRA unless such company is known to the general public. Consequently there is a higher possibility of facing obstruction in case of availing protection under the anti-dilution statutes by such companies over those which are retail labels.

Let us consider an example of the above mentioned. 'Qualcomm' is one of the leading companies that deal in telecommunication products. But they mostly do business with the leading corporations dealing in wireless electronic products like mobile devices not in direct business with the individual consumer. Now it is a very well -known brand within the said industry but it cannot avail the protection under anti-dilution statutes unless it is recognized and identified by the usual consumer.

The courts while applying the TDRA followed the eight factors to be taken into considerations vis-à-vis fame. But under the new Act the factor of regional fame could not be applied therefore the mark ' $W A W A^{37}$ could not any longer be considered as a famous mark. Similarly the mark "NAILTIQUES'38 could not meet the requirement of fame under the TDRA which were otherwise considered by some courts as famous marks under the FTDA. On the Contrary marks like 'NIKE'39 and "LOUIS VUITTON" ${ }^{30}$ were able to meet the fame requirement under the TDRA.

\section{E. Introduction of dilution in India}

The Indian courts were tremendously burdened to analyze and include the problem of dilution within the trademark legal system before the enactment of the Trademarks Act 1999 as the earlier statute governing the law of trademark which is Trade and Merchandise marks Act 1958 fell short of including the required provisions to deal with the problem of dilution. Even though the Indian courts have acknowledged the concept of dilution as early as in the 1990's there was a lack of analysis of such doctrine in the judgments declared by them.

It was in the case of 'Daimler Benz. Aktiegesellschaft v. Hybo Hindustan"1 that for the first

\footnotetext{
36 TCPIP Holding Company, Inc. v. Haar Communications Inc., 2001, 244 F.3d 88, p. 90.

37 Wawa Dairy Farms v. Haaf, 1996, 40 U.S.P.Q.2d 1629, p. 1630.

38 Nailtiques Cosmetic Corp. v. Salon Sciences Corp., 1997, 41 U.S.P.Q.2d 1995, p. 1995.

39 Nike, Inc. v. Nikepal Intern., Inc., 2007, 84 U.S.P.Q.2d 1820, p. 1820.

40 Louis Vuitton Malletier v. Haute Diggity Dog, 2007, 507 F.3d 252, p. 253.

41 Daimler Benz v. Hybo Hindustan, Delhi High Court, India, 1994 A.I.R. 239, p. 239.
} 
time the defendant was prohibited from using the plaintiffs' mark but the concept of likelihood of confusion or deception was not drawn in the case.

In the given case the use of the mark BENZ was not allowed by the defendant on undergarment. Even though the doctrine of dilution was applied yet the word dilution was not used anywhere by the Hon'ble Judge throughout the judgment except towards the end where he stated: "In my view, the defendant cannot dilute that by user of the name "Benz" with respect to a product like under-wears."

Although this was the first case where the court employed the principle of dilution yet the judgment concentrated more on the unfairness of the use of the mark if permitted to use and no evaluation of the dilution or related principles was made by the court.

The Court observed that: "Such a mark is not up for grabs—not available to any person to apply upon anything or goods. That name... is well known in India and worldwide, with respect to cars, as is its symbol a three pointed star". ${ }^{42}$

An analysis of the judgment highlights that the court reached the decision keeping in mind the exceptional position which has been acquired by the brand Benz and how unfair it would be to allow some third party to use it on his commodities.

In the above mentioned cases the courts failed to investigate the theoretical contrasts between encroachment, passing off and weakening of trademark that is dilution. On analysis of the cases it becomes quite evident that before the Trademarks Act of 1999 was established, the Indian courts connected the custom-based law cure of passing off to achieve findings of weakening as an action of unfair contest. Along these lines, unmistakably before the Act of 1999 was instituted, Indian High Courts frequently got itself perplexed between the ideas of 'weakening' and 'passing off'. The principle of dilution was created by our courts, having considered the universally perceived benchmarks about the need to ensure protection for the famous marks whose abuse, in connection to different or non-competing products or services could "dilute" its allure.

\section{F. Indian Scenario After Trademarks Act, 1999}

When speaking of trademark dilution, section 29(4) of the Trademarks Act 1999 comes to our mind. Sections 29(4) of the Trademarks Act, 1999 was introduced with a view to initiate and present the idea of trademark dilution in India. The area is what might as well be equated with segment 10(3) of the United Kingdom's Trade Marks Act of 1994. ${ }^{43}$ The essential goal of weakening as a type of encroachment under Section 29(4) is to give more extensive assurance to well-known trademarks without the necessity of 'probability of perplexity'; thus security is with respect to dissimilar products. Along these lines, the test of 'probability of confusion' has not been specified in this section.

It is important to take note that the law of Section 29(4) of the Trademarks Act,

\footnotetext{
$42 \quad$ Ibid.

43 The Trade Marks Act, 1994, United Kingdom, s. 10(3).
} 
1999 is still in its maturing stage as relatively few cases have touched base to the courts managing this issue till now. The structure of the arrangement of Section 29(4) managing trademark weakening dilution passes on the legislative aim in regards to the norms required to ascertain weakening of trademarks, regarding disparate items. In any case, regardless of the presence of clear statutory rules, the judiciary keeps on rendering choices under defective comprehension of the idea of trademark weakening.

For the purpose of grasping how the court declared judgment on the basis of faulty understanding of the dilution theory, it is pertinent to analyze and examine the case of "Hamdard National Foundation v. Abdul Jalil"'44. In this case the plaintiff's well-known mark 'HAMDARD' was used by the defendant on Basmati rice, as a result the plaintiff who was the owner of the mark and used it in respect of Unani medicines filed an infringement suit.

Here again the court decided the case on faulty understanding and stated that what summed up to trademark infringement in relation to non-competition goods was "likelihood of deception". It is already quite clear and evident that section 29(4) does not need the proof of deceptive resemblance. Reliance was based incorrectly on the definition of "deceptive similarity" given under section 2(1) (h).

In "Ford Motor Co. v. C.R. Borman" 45 a case was filed by the plaintiff for infringing the mark 'FORD'. On appeal it was stated:

It is to be noted that Section 29(4) is clearly an exception to the structure of the Act and applies only to those marks which have gained a reputation in India. As a result the plaintiffs do not have to show deception on the side of the Defendants or likelihood of the consumer being deceived because of the application of the trademark in question.

Along these lines, unmistakably not at all like in the choice of the High Court in the Hamdard National Foundation case, the Court for this situation entirely took after the dialect of Section 29(4) of the Act of 1999 and watched that if the trademark is notable in India and has reputation, the offended party does not need to build up the defendant's deception. Despite the fact that, for this situation, the Court entirely took after the genuine applicable arrangement of the Act of 1999, to manage the issue of trademark weakening, the judgment still did not have the authoritative value since the benefits of the case were scarcely examined by the court.

\section{Comparative Analysis of the Laws Of Dilution of India and USA}

Dilution as a separate form of infringement was recognized and introduced much later in India than the USA. Even though the laws relating to dilution in both India and USA both aim to prohibit the weakening of the singularity of the strong mark which has established its goodwill and reputation among a considerable amount of

\footnotetext{
44 Hamdard National Foundation v. Abdul Jalil, High Court of Delhi, India, IA 7385/2004 IN CS(OS) 1240/2004.

45 Ford Motor Co. v. C.R. Borman, High Court of Delhi, India, 2008, (38) PTC 76, p. 77.
} 
consumers which makes it unique and distinct, there exist few dissimilarities between the provisions of both. Following are the dissimilarities which can be observed by going through the anti-dilution provisions:

\section{A. Famous and Mark with Reputation}

The principle of dilution is applicable to any mark only when the mark is either famous or well-known or has a global reputation. There has been a lot of debate among the scholars regarding the difference between a well-known mark, famous mark and a mark with reputation. Often the terms well-known and famous are used interchangeably but there exists a slight variation among the two.

A well-known mark is one which is usually known to a sizable section of the public with respect to such goods and services. A famous mark is one which is applied to such commodities or services which have been sold internationally and is usually recognized as an indicator of a certain level of quality assurance. Famous marks are repeatedly considered as a specific kind of well-known mark and that they usually are regarded as marks of advanced reputation and therefore relish a widened angle of protection.

Dilution legislation in the USA provides protection against dilution only to famous marks. So for a mark to be protected under the anti-dilution statute it must satisfy the criteria of being famous. But when coming to India it has been observed that most of the times drawing distinction between famous and well-known marks have not been done successfully by the courts in India and generally the application of standard has been the level or standard applied in case of well-known marks. In the statutory provision it is clearly stipulated that in India for a mark to be protected under the Antidilution provisions it must have a reputation in India. ${ }^{46}$

\section{B. Standard of Harm}

Subsequent to the famous Moseley ${ }^{47}$ in the USA it was established that for a claim of dilution the owner of the famous mark need not show actual dilution anymore. The judgment in the abovementioned case clarified the long continuing confusion of the standard of harm required to prove dilution. It was stated that "possibility of dilution" would hereafter be enough and sufficient to claim an act of dilution and the need to show real monetary damage was no longer the basic requirement.

When talking about India, the standard of injury has not clearly been given in the provisions. It is simply specified that the application of the junior mark is such that it is unfavorable to the singularity of the original mark or in some or other damaging the status and name built by such brand globally over a period of time. Even though we can find more similarities in respect to the harm standard in both USA and India as in

\footnotetext{
46 The Trademark Act, 1999, India, s. 29(4).

47 Moseley v. V Secret Catalogue Inc., 2003, 537 U.S. 418, p. 420.
} 
both cases actual injury is not necessary but the only differentiating factor would be in case of India it can be formulated based on construction of the provision rather than any explicit wording.

\section{Defenses and Fair Use}

Under the Trademark Dilution Revision Act of 2006, explicit provisions have been included in respect to fair use principle thereby providing defenses for some acts from the action of dilution. Some of the acts included in the defenses under the claim of fair act are marketing or publicity that allows purchaser to equate or match commodities or services also includes parodying, critiquing or remarking on the famous mark's proprietor or his products or facilities etc. are excused from the ambit of dilution by distorting or damaging the repute. ${ }^{48}$

The Indian law differs completely from the dilution laws in the USA in this aspect. The Act on trademarks in India fails completely to provide any of such exceptions or defenses. Under the present Trademarks Act 1999 there are provisions which expressly state that a "registered trademark" is violated by any marketing or promotion of that recorded trademark "if such advertising is detrimental to its distinctive character; ${ }^{49}$ or is against the reputation of the trademark." ${ }^{50}$ So basically it means that relative marketing and justified use of any registered trademark is prohibited as per the above mentioned provisions.

The Indian law however did not provide for such exemption. However, marks, which were not considered as infringing marks before the 1999 Act, are exempted from any infringement action. The inclusion of this provision is ambiguous and defeats the very purpose of protection against dilution. This paper suggests the repeal of this provision and the inclusion of a more concrete exemption clause in the light of fair use doctrine.

\section{Types of Dilution}

The Trademark Dilution Revision Act (TDRA) 2006 brought about quite a number of changes in the Federal Trademark Dilution Act (FTDA) of 1996. One of the remarkable inclusions is the explicit definition of dilution by blurring and dilution by

48 The Lanham (Trademark) Act, 1946, United States of America, s. 43 (c)(3) reads: (3) Exclusions The following shall not be actionable as dilution by blurring or dilution by tarnishment under this subsection:

(A) Any fair use, including a nominative or descriptive fair use, or facilitation of such fair use, of a famous mark by another person other than as a designation of source for the person's own goods or services, including use in connection with-

(i) advertising or promotion that permits consumers to compare goods or services; or

(ii) identifying and parodying, criticizing, or commenting upon the famous mark owner or the goods or services of the famous mark owner.

(B) All forms of news reporting and news commentary.

(C) Any noncommercial use of a mark.

49 The Trademark Act, 1999, India, s. 29(8)(b).

50 The Trademark. Act, 1999, India, s. 29(8)(c). 
tarnishment. But to claim dilution by blurring under TDRA the plaintiff must prove two essentials. First there should be a link between the blurring mark and the mark which is being blurred ${ }^{51}$ and secondly the blurring mark must necessarily prejudice the original mark. ${ }^{52}$ Under the Indian law the dilution provision implies the existence of the two types of blurring from the language "detrimental to the distinctive character" 53 or "reputation of the registered trademark" 54 but without expressly using the term blurring or tarnishment anywhere in the statute.

\section{Emerging Issues of Trademark Dilution in India}

This era has witnessed a sudden increase in globalization. Globalization in trade and commerce has opened new doors and avenues for manufacturers to get global recognition for their products. This eventually leads to creation of brand name and worldwide identity. In such a scenario it becomes important for the owners to be able to protect their highly reputed marks from being watered down by unpermitted use by anyone else. The singularity associated with such a mark is what makes it a global brand and is easily identified by the consuming public. Even though dilution has been identified and later recognized as a separate form of infringement and consequently anti-dilution laws have been passed accordingly but time and again issues have either found their way through the persisting gaps of such statute or have been observed as a continuing root of dispute.

Although the concept of Dilution is not explicitly mentioned in the Indian laws or in the international law, the statutory requirement in the Indian laws and TRIPs agreement does not require the mark to be a publicly recognized one. Also the reputation requirement is not as strict as that mentioned in the US laws. This is quite apparent from the examination of the sections present in the Indian Trademark Act ${ }^{55}$ and the TRIPS provisions specifying the criteria to be fulfilled for a mark to be recognized as a well-known mark. Both these acts require acknowledgement and presence of goodwill amongst the relevant group of people in the society. The ambit of the recognition of the mark among the relevant people is limited to a smaller section in society while the US requirement of "wide recognition among the general consuming public" has a much larger scope.

The Indian scenario is much more grave because the criteria of recognition among the relevant sector of the society is not very strict and quite liberal as per the definition provided in the Indian laws. The India legislative along with the WIPO/Paris Union Joint Recommendation, ${ }^{56}$ states that territory where the trademark is required to be

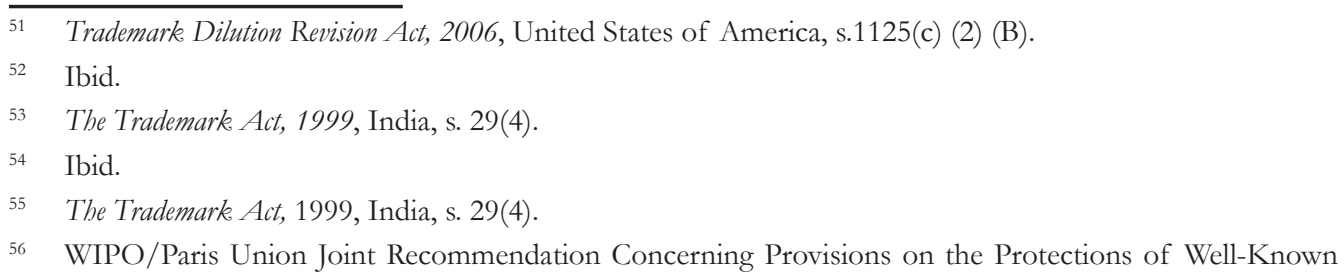


famous in at least one sector of the public in India by the direction of the court or registrar, then the said mark can be termed to be a well-known mark. These criteria further limit the ambit of recognition of the mark and consequently additionally debilitates the protective measures that are needed to defend the mark under the principles of dilution. Thus applying these laws to that of dilution disputes can have terrible outcomes. However if we envision the explanation provided in the Trademark Act, 1999 it only says about protection of well-known marks or that of mark bearing word wide reputation, we can observe that the ambit of this provision is limited in front of the criteria mentioned under the principles of dilution.

Again another section in the Trademark Act, 1999 regarding the matter under thought is section 29, which expresses that an registered trademark having good will in India is encroached on account of utilization of an similar or dissimilar by an individual who utilizes it over the span of business, if such utilization is without due reason and "takes unfair advantage of" or is hindering the exclusivity or good will of the registered trademark. ${ }^{57}$ Unlike alternate sections which are managing infringement, there is no necessity of confusion in this area. This section is extremely befuddling as it attempts to forestall utilities on dissimilar products or services, of imprints which have goodwill in India, if such act is devoid of proper authorization or to enjoy unfair benefit or even has the intention to harm the good name of the product in the market. It is a general section.

The definition of well-known mark, provided in Section 2(1) (zg) is equivocal as in it didn't explain the factor for deciding if a mark is well known or not. The Court from numerous points of view can interpret the understanding of the word and it might cause difference in opinion. Hence, an appropriate rule or determining factor for well-known trademarks is required with a specific end goal to evade irregularity and vagueness.

The vagueness in the meaning of well-known trademarks has likewise disturbed the implementation of section $11^{58}$. In spite of the fact that response is taken to Sub section 6, 7 and 9 while deciding if a mark is well recognized or not. The rules given under these demonstrations are subjective in nature and interpretation of the Court is crucial. This boosts the necessity of having proper regulation to determine the criteria for a well-known mark which shall be helpful to manage cases pertaining to the principle of dilution.

\section{Conclusion}

An analysis of the principle of dilution and the existing laws provides that undoubtedly that the accurate receiver of the protection under anti-dilution statute can only be such

\footnotetext{
Marks adopted by the Assembly of the Paris Union for the Protection of Industrial Property and the General Assembly of the World Intellectual Property Organization (WIPO) at the Thirty-Fourth Series of Meetings of the Assemblies of the Member States of WIPO Sept 20 to 29, 1999.

57 The Trademark. Act, 1999, India, s. 29(4).

58 The Trademark Act, 1999, India, s. 11.
} 
marks which are either famous, well-known or has a certain level of reputation among the consumer. Dilution cannot be equated with traditional infringement keeping in mind the intensity of investment made by the proprietor from monetary as well as time consuming aspect to make sure such mark crosses the niche fame criteria and becomes a brand renowned globally in assuring certain standard of quality to its purchaser. As a result such marks can easily be the target and the reputation or the status earned by such marks is often attempted to be used by unauthorized parties.

It stated that the new Trademark Act 1999 is a stage forward in prohibiting the weakening yet at the same time the contemporary Indian situation requires for a different lawful sanctioning for counteractive action of weakening and to meet the standard of assurance in the worldwide level. The following suggestions can be put forth and be considered to eradicate the existing challenges and hurdles present in the current scenario and laws and to ensure to make the doctrine of dilution more consistent, dependable and independent form of claim:

- When we read section 11 and section 29 (4) we clearly observe that there exists some sort of resistance between the two. The reason for this would be that one speaks of well-known marks while the other concentrates on marks with reputation. The two provisions are therefore in conflict with each other. This leads to inequalities between the opinion and actions of the courts as it can cause randomness. Also a closer look and a deeper understanding of the two provisions reveal that law in India is still on "trans border reputation" and instead marks of such nature which can be regarded as global are usually sheltered only under passing off. It is therefore suggested that the term marks with reputation in Section 29(4) should be replaced with the term "wellknown" to provide a wider recognition and to provide a broader subject matter of safeguard to such marks which have global status.

- The vagueness in the meaning of well-known marks has likewise disturbed the enforcement requirement of Section 11. In spite of the fact that recourse is taken to Sub section 6,7 and 9 while deciding if a trademark is well-known or not. The rules given under these Act are subjective in nature and elucidation of the Court is required. This stresses on the prerequisite of a particular deciding element for well-known marks which may bring about precise decisions while managing the instance of protection against weakening.

- The Act gives security just to registered marks and is quiet about unregistered stamps regardless of its notoriety. Despite the fact that the passing off activity fills in for this lacuna, it is alluring to have a statutory arrangement in such a manner. Along these lines, this paper recommends for an administrative change, giving security to unregistered trademarks, in this manner diminishing the reliance on passing off standards.

- Section 28 (b) and (c) are two such provisions which according to the researcher's suggestion might need some modification. This provision states that a "registered trademark" will be encroached or violated by advertising of such trademark provided such: 
i. Encroachment is damaging the distinctiveness of the registered mark or;

ii. Is injurious to the reputation of the registered mark; so basically this provision puts a restriction on comparative advertisement or any kind of fair use of such registered marks.

When the same is equated with the U.S. laws of dilution we find that in the United States comparative advertising is allowed and is included in fair use and it lets the consumer compare the goods and services also to make parody or criticize, comment or news report in respect to such mark. This provision therefore accords unqualified property right on every proprietor of trademark. The concern which this section raises is that in future it might lead to a restrain on the freedom of speech. Therefore a section of such nature should be eliminated keeping the above in view.

Apart from the Indian laws the paper has also focused on the issues persisting in the dilution laws in the United States under the TDRA. Based on such issues the following suggestions can be furnished.

- Under the TDRA another point to be noted is that court has adequate prudence in considering the variables said under the Act for deciding blurring and notoriety, and it isn't compulsory for the court to adhere to these factors to reach to a conclusion at the assurance of blurring and popularity on those important elements expressed under the Act. The issue with an excess of discretion, in any case, is that it will welcome the judges to choose arbitrarily. This paper additionally recommends that consideration of significant factors under the Act should be made obligatory for the courts as an excessive amount of discretion opens the entryways for randomness.

- Another gap present under the Act is that it doesn't give any elements to determine weakening by tarnishment. The Act accommodates estimation of weakening by blurring by method for a multi factor test i.e. factors are given under the Act to demonstrate blurring, while there are no variables given under the Act to demonstrate weakening by tarnishment. Here too the court has power to calculate it as per its will and discretion as no measuring stick is given. Accordingly, conflicting judgment of various courts identifying with measurement of weakening by tarnishment is normal; as there is no uniform standard or measuring stick to decide the same. This yet again makes the parties to the case victims of ambiguity and randomness of the court. Thus, this paper proposes that the Act be corrected to give particular factors to estimating of weakening by tarnishment and it be made obligatory for the court to construct it's estimation in light of those elements as it were.

- The offended party is required to indicate the relationship between the two marks keeping in mind the end goal to get alleviation under the Act for blurring or tarnishment. Regardless of whether the mark is like that of the offended party's popular mark, no alleviation is allowed until the point when affiliation 
isn't evidenced. This has been included under the Act as a superfluous necessity. In the fallout of Moseley, a few court hosts inferred that if the parties' imprints are indistinguishable, at that point blurring might be assumed. Be that as it may, this assumption isn't perceived by the Act, consequently provision of the Act is conflicting with the assumption. It is recommended that if an offended party demonstrates the comparability between two marks, it ought to be formally chosen in the support of the offended party and alleviation must be without a doubt, there ought to be no compelling reason to demonstrate association alongside similarity.

From the above mentioned it is quite evident that in spite of enacting Acts and inclusion of appropriate provisions in absence of the necessary modification needed famous or well-known marks cannot be completely protected under the dilution laws in a complete lack of hurdles or issues. Establishing an Act won't suffice if such is not free of loopholes and legal gaps. Mark A. Lemley was of the view that if the courts are not cautious to keep check on the new doctrine, it will soon take a life of its own. 